\title{
THE EFFECT OF SAUNA BATHING ON LIPID PROFILE IN YOUNG, PHYSICALLY ACTIVE, MALE SUBJECTS
}

\section{DOROTA GRYKA, WANDA PILCH, MARTA SZAREK, ZBIGNIEW SZYGULA, and ŁUKASZ TOTA}

University School of Physical Education, Kraków, Poland

Institute of Biomedical Sciences

\begin{abstract}
Objectives: The aim of the study was to evaluate effects of Finnish sauna bathing on lipid profile in healthy, young men. Material and Methods: Sixteen male subjects (20-23 years) were subjected to 10 sauna bathing sessions in a Finnish sauna every 1 or 2 days. The mean sauna temperature was $90 \pm 2{ }^{\circ} \mathrm{C}$, while humidity was $5-16 \%$. Each session consisted of three 15-minute parts and a 2-minute cool-down between them. The following measurements were taken before and after the sauna sessions: body mass, heart rate, body skinfold thickness. The percentage fat content and then, the lean body mass were calculated. Total cholesterol, triacylglycerols, lipoprotein cholesterol LDL and HDL were measured in blood samples. Results: A statistically significant decrease of total cholesterol and LDL cholesterol was observed during 3 weeks of sauna treatment and in the week afterwards. A significant decline in triacylglycerols was found directly after the $1 \mathrm{st}$ and $24 \mathrm{~h}$ directly after the 10th sauna session. After the 10th sauna session the level of HDL cholesterol remained slightly increased, but this change was not statistically significant. A decrease in blood plasma volume was found directly after the 1st and the last sauna bathing session due to perspiration. An adaptive increase in blood plasma volume was also found after the series of 10 sauna sessions. Conclusions: Ten complete sauna bathing sessions in a Finnish sauna caused a reduction in total cholesterol and LDL cholesterol fraction levels during the sessions and a gradual return of these levels to the initial level during the 1st and the 2nd week after the experiment. A small, statistically insignificant increase in HDL-C level and a transient decline in triacylglycerols were observed after those sauna sessions. The positive effect of sauna on lipid profile is similar to the effect that can be obtained through a moderate-intensity physical exercise.
\end{abstract}

Key words:

Human lipid profile, Sauna, Plasma volume

\section{INTRODUCTION}

Proper blood levels of total cholesterol, triacylglycerols, low-density lipoprotein cholesterol (LDL-C) and highdensity lipoprotein cholesterol (HDL-C) fractions are crucial in full readiness of an athlete to face challenges. Moreover, during physical exercise they ensure optimal utilization of energy sources present in the body (such as carbohydrates and fat) [1]. Although physical activity is one of the components of health prevention recommended in order to improve blood lipid indices, the research studies carried out in recent years have demonstrated that not all types of physical exercise have positive effect on the lipid profile. Sports disciplines that utilize the energy supplied chiefly from anaerobic sources are among those types of exercise which disturb proper lipid profiles in athletes [2-4].

On the other hand, physical inactivity and sedentary lifestyle have become a global problem being one of the main risk factors for developing obesity, cardiovascular diseases, stroke, type 2 diabetes and dyslipidemia [5,6]. However,

This work was financially supported by grant No. 23/BS/IFC/2011. Manager of grant: Wanda Pilch, PhD.

Received: November 6, 2013. Accepted: April 14, 2014.

Corresponding author: D. Gryka, Institute of Biomedical Sciences, University School of Physical Education, Jana Pawła II 78, 31-571 Kraków, Poland (e-mail: dorota.gryka@awf.krakow.pl). 
there are people that cannot exercise because of age, injury or dysfunction of motor organs. An increasing body of evidence indicates that in such cases, concerning contraindications for sauna, people might benefit from taking sauna baths as it provides stimulus for sympathetic nervous system and elicits, to certain degree, some physiologic responses that have been observed during exercise $[7,8]$. The response to sauna-specific hyperthermia observed in human body has been extensively explored in many scientific publications. The studies have demonstrated on the one hand, a positive effect of sauna bathing on the cardiovascular and respiratory systems, motor organs and overall well-being of the sauna users and justifiable contraindications on the other [9-12]. However, there were few reports on the effect of regularly repeated sauna sessions on lipid profile in healthy subjects. The aim of the present study was to evaluate short-term and long-term effects of sauna sessions on lipid profile in young, healthy and physically active men.

\section{MATERIAL AND METHODS}

\section{Study group}

The study focused on a group of 16 physically active, nonsmoker, male subjects aged 20 to 23 years. Physical activity of the subjects was estimated using the International
Physical Activity Questionnaire (IPAQ). The research group consisted of men being classified to the category "moderate physical activity" (category 2) according to the self-reported activity data from the short IPAQ form "last 7d recall" recommended by the authors [13].

The group was selected according to similar body build and content of fatty tissue. Anthropometric characterization of men is provided in Table 1. Before the experiments, all the volunteers had undergone medical examinations, which evaluated their health status (no contraindications against to sauna bathing were diagnosed).

The subjects were advised not to change their everyday diets, not to take dietary supplements during the experiments and not to use alcohol. The subjects were also asked to fill in a questionnaire in order to evaluate individual daily intake of food products and their type. The data collected in the questionnaire were used to compute an average level of nutrient intake in terms of energy value and the content of protein, fat and carbohydrates. The computations were carried out by means of a computer software Wikt 1 and "Tabele wartości odżywczej produktów spożywczych" (Tables of nutritive value of food products) $[14,15]$.

In accordance with the Helsinki Declaration of 1975, revised in 1983, before commencement of the study the participants were informed about the purpose of the study

Table 1. Characteristics of the study group $(\mathrm{N}=16)$

\begin{tabular}{lccc}
\hline \multicolumn{1}{c}{ Variable } & $\begin{array}{c}\text { Before the study } \\
(\mathrm{M} \pm \mathrm{SD})\end{array}$ & $\begin{array}{c}\text { After the study } \\
(\mathrm{M} \pm \mathrm{SD})\end{array}$ & $\mathrm{p}$ \\
\hline Age $(\mathrm{years})$ & $20.88 \pm 0.89$ & - & - \\
BH $(\mathrm{m})$ & $1.81 \pm 0.04$ & - & - \\
BM $(\mathrm{kg})$ & $74.69 \pm 7.61$ & $74.76 \pm 8.11$ & 0.918 \\
BMI $\left(\mathrm{kg} / \mathrm{m}^{2}\right)$ & $22.82 \pm 1.55$ & $22.83 \pm 1.67$ & 0.834 \\
FAT $(\%)$ & $10.10 \pm 2.45$ & $9.93 \pm 2.94$ & 0.877 \\
FAT $(\mathrm{kg})$ & $7.66 \pm 2.65$ & $7.59 \pm 3.14$ & 0.979 \\
LBM $(\mathrm{kg})$ & $67.04 \pm 5.59$ & $67.18 \pm 5.60$ & 0.717 \\
\hline
\end{tabular}

BH - body high; BM - body mass; BMI - body mass index; FAT - body fat; LBM - lean body mass.

$\mathrm{M}$ - mean; SD - standard deviation. 
and the possible risks involved in it and their written consent was obtained. The project was approved by the Bioethics Committee at the Regional Medical Chamber in Kraków (No. 66/KBL/OIL/2011).

\section{Research protocol}

Each subject, every 1 or 2 days was subjected to 10 sauna bathing sessions in a traditional Finnish sauna. The mean temperature in a sauna chamber at the face level was $90 \pm 2^{\circ} \mathrm{C}$, while air humidity ranged from $5 \%$ to $16 \%$. Each sauna bathing session was divided into three 15 -minute parts followed by a 2-minute cool-down in a stream of cold water (temp. $20^{\circ} \mathrm{C}$ ). The subjects did not drink anything during the sauna sessions. The following anthropometric measurements were taken before and after the sauna sessions: body mass (BM, using Sartorius F1505-DZA with accuracy of $0.01 \mathrm{~g}$ ), body height (BH, accuracy of $1 \mathrm{~cm}$ ) and skinfold thickness (by means of Harpenden skinfold calliper) on the left side of the body. Rectal temperature of the subjects during the 1st and the last sauna bathing was monitored with Ellab (Denmark) MRV-A Electrothermometer. The percentage fat content $(\% \mathrm{~F})$ and then the lean body mass (LBM) were calculated according to the Slaughter's formula [16]:

$$
\% \mathrm{~F}=1.21(\mathrm{TRC}+\mathrm{SSC})-0.008(\mathrm{TRC}+\mathrm{SSC})^{2}-5.5
$$

where:

$\% \mathrm{~F}$ - percentage content of fat tissue,

TRC - triceps skinfold - vertical fold, located on the posterior midline of the upper arm, measure halfway between the acromion (bony point of the shoulder) and olecranon processes (bony point of the elbow), arm held freely to the side of the body, SSC - suprascapular skinfold - diagonal fold, located 1-2 cm below the inferior angle of the scapula (the bottom of the shoulder blade).

Venous blood samples were taken at the baseline and next stages of the study were performed according to the research protocol presented in Table 2. Blood was sampled from 8:00 a.m. to 10:00 a.m. and the subjects participated in the experiment on empty stomachs.

Table 2. Study protocol in chronological order

\begin{tabular}{|c|c|c|}
\hline Day of the study & Symbol & Study protocol \\
\hline \multirow[t]{3}{*}{$1 \mathrm{st}$} & A & blood sampling before the 1st sauna session \\
\hline & & 1st sauna session \\
\hline & B1 & blood sampling $10 \mathrm{~min}$ after the 1st sauna session \\
\hline 2nd & B2 & blood sampling $24 \mathrm{~h}$ after the 1 st sauna session \\
\hline 3rd-18th & & 2nd-9th sauna sessions in 1-day intervals (without blood sampling) \\
\hline \multirow[t]{3}{*}{ 19th } & B3 & blood sampling before the 10th sauna session \\
\hline & & last (10th) sauna session \\
\hline & B4 & blood sampling 10 min after the last sauna session \\
\hline 20th & B5 & blood sampling $24 \mathrm{~h}$ after the last sauna session \\
\hline 21st-26th & & break \\
\hline 27 th & B6 & blood sampling 1 week after the last sauna session \\
\hline 28th-33th & & break \\
\hline 34th & B7 & blood sampling 2 weeks after the last sauna session \\
\hline
\end{tabular}

A - initial value; B1 - 10 min after the 1st sauna bathing session; B2 - $24 \mathrm{~h}$ after the 1st session; B3 - before the last session; B4 - 10 min after the last session; B5 - 24 h after the last session; B6 - a week after the last session; B7 - 2 weeks after the last session. 
In blood samples the following blood lipid indices were measured: total cholesterol (TC), triacylglycerols (TAG), low-density lipoprotein cholesterol (LDL-C), high-density lipoprotein cholesterol (HDL-C) and total protein levels in order to evaluate changes in plasma volume ( $\% \Delta \mathrm{PV})$ evoked by dehydration after intensive perspiration typical of sauna bathing. Due to dehydration, blood levels of total cholesterol, HDL and LDL cholesterol fractions and TAG from B1 and B4 samples (directly after the 1st and the 10th session) were corrected using the $\% \Delta \mathrm{PV}$ index calculated by means of the following formula [17]:

$$
\% \Delta \mathrm{PV}=\left(\frac{\mathrm{P}_{\text {pre }}}{\mathrm{P}_{\text {post }}} \times 100\right)-100
$$

where:

$\mathrm{P}_{\text {pre }}$ - pre-exposure protein concentration,

$\mathrm{P}_{\text {post }}$ - post-exposure protein concentration.

The corrected values were computed using the KraemerBrown formula [18].

\section{Statistical analysis}

Statistical analysis of the results was carried out using the Statistica 10 software package. Consistency of distribution of the variables with normal distribution was tested by means of the Shapiro-Wilk test. Because the distribution was not normal, evaluation of the significance of differences used non-parametric tests. Data comparison was carried out using the Wilcoxon signed-rank test. The level of significance was set at $\mathrm{p}<0.05$ as statistically significant. All the results were presented in a form of mean \pm standard deviation $(\mathrm{M} \pm \mathrm{SD})$.

\section{RESULTS}

Anthropometric characterization of the male group studied as presented in Table 1, showed no significant changes in body build observed with respect to the body mass, BMI, fatty tissue or fat free mass of the subjects after a series of sauna sessions.

Analysis of the diets among the men studied with regard to the energy and nutrient intake did not reveal discrepancies in the values considered as recommended for men from this age group with respect to the physical activity level (PAL) of 1.70-1.99 ("Classification of physical activity levels" according to $\mathrm{FAO} / \mathrm{WHO} /$ UNU 2004) [14]. The mean nutrient intake, calculated per $1 \mathrm{~kg}$ body mass, among the men studied is presented in Table 3.

The results that characterize lipid profile during and after sauna sessions are presented in Figures 1-4. Analysis of the results revealed a considerable variation of individual concentrations of lipid profile fractions during the experiment. A statistically significant decline in triacylglycerols (TAG) was found compared to the initial levels (A) that amounted to $1.08 \pm 0.43 \mathrm{mmol} / \mathrm{l}($ mean $\pm \mathrm{SD}) \mathrm{di}$ rectly after the 1 st sauna session (B1): $0.91 \pm 0.27 \mathrm{mmol} / \mathrm{l}$ $(\mathrm{p}=0.002)$, and $10 \mathrm{~min}$ after the 10th sauna session (B4): $0.80 \pm 0.23 \mathrm{mmol} / \mathrm{l}(\mathrm{p}=0.003)$ as well as after $24 \mathrm{~h}$ (B5): $0.90 \pm 0.42 \mathrm{mmol} / \mathrm{l}(\mathrm{p}=0.034)$ with respect to the initial value (Figure 1). The value of TAG levels during 2 consecutive weeks after completion of the sauna sessions were lower than the initial value but the differences

Table 3. Energy and nutrients intake in the diets of the study group

\begin{tabular}{lc}
\hline \multicolumn{1}{c}{ Energy and nutrients intake } & $\mathrm{M} \pm \mathrm{SD}$ \\
\hline Energy $(\mathrm{kcal})$ & $3412.63 \pm 545.79$ \\
Energy/kg of body mass $(\mathrm{kcal})$ & $45.89 \pm 1.72$ \\
Carbohydrates $(\mathrm{g})$ & $438.73 \pm 18.12$ \\
Carbohydrates/kg of body mass $(\mathrm{g})$ & $5.94 \pm 0.28$ \\
Protein $(\mathrm{g})$ & $99.91 \pm 2.12$ \\
Protein/kg of body mass $(\mathrm{g})$ & $1.34 \pm 0.02$ \\
Fat $(\mathrm{g})$ & $128.91 \pm 7.24$ \\
Fat $/ \mathrm{kg}$ of body mass $(\mathrm{g})$ & $1.72 \pm 0.06$ \\
\hline
\end{tabular}

Abbreviations as in Table 1. 


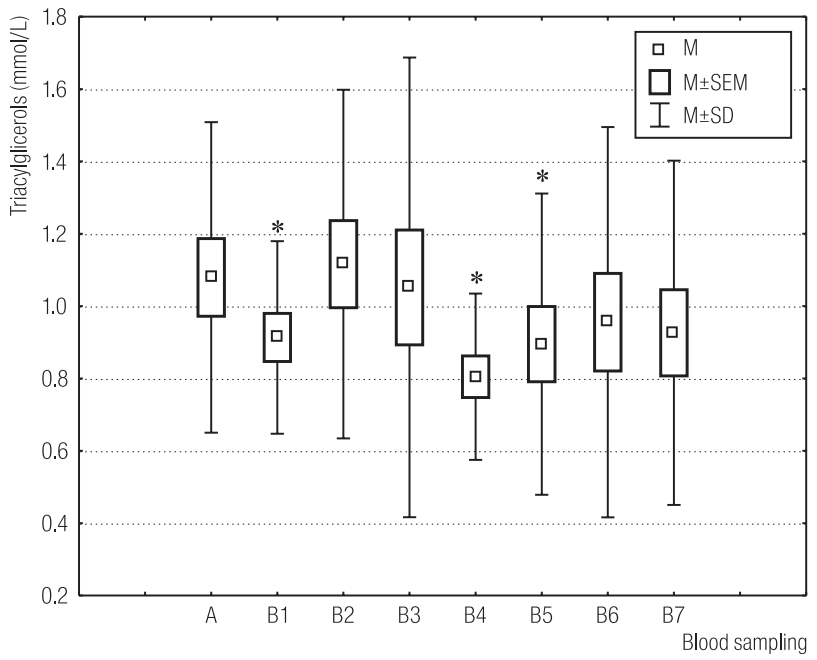

* Statistical significance of differences compared to the A value at $\mathrm{p}<0.05$.

SEM - standard error of the mean.

Other abbreviations as in Tables 1 and 2 .

Fig. 1. Triacylglycerols (TAG) levels during sauna bathing

were not statistically significant (B6: $0.96 \pm 0.54 \mathrm{mmol} / \mathrm{l}$ and B7: $0.93 \pm 0.48 \mathrm{mmol} / \mathrm{l})$.

A statistically significant decline in the level of total cholesterol compared to the initial value (A: $4.50 \pm 0.66 \mathrm{mmol} / \mathrm{l}$ ) was reported directly after the 1st sauna session

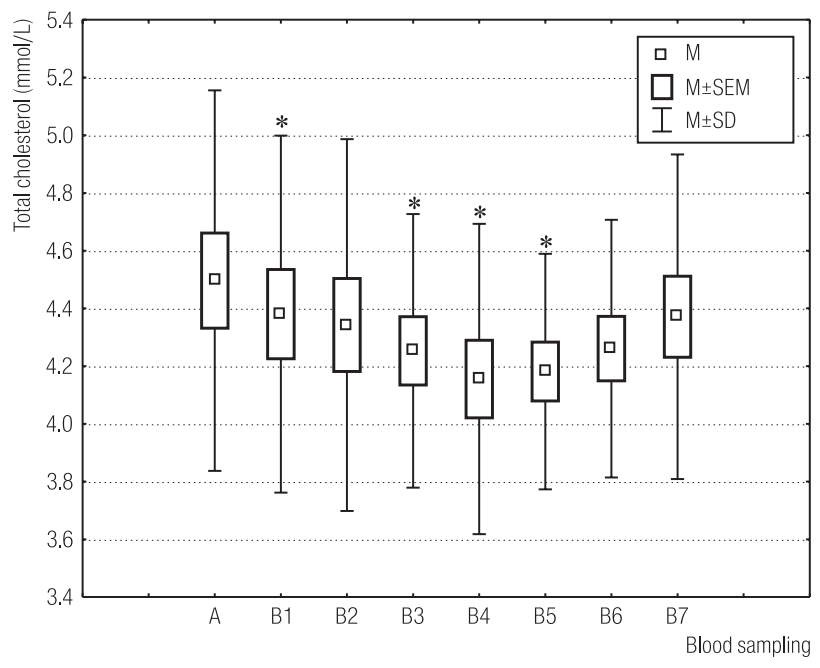

Abbreviations as in Tables 1, 2 and Figure 1.

Fig. 2. Total cholesterol (TC) levels during sauna bathing

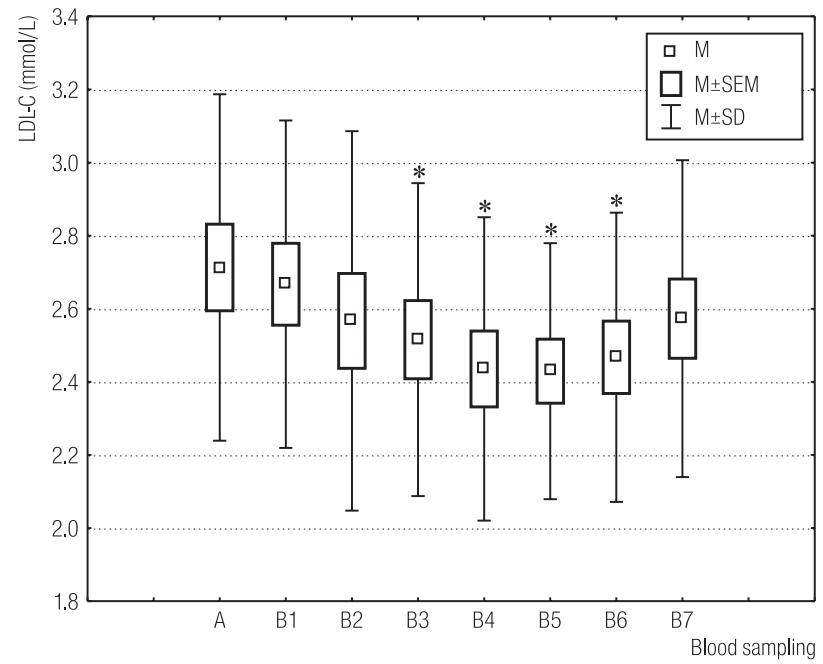

Abbreviations as in Tables 1, 2 and Figure 1.

Fig. 3. Low-density lipoprotein cholesterol (LDL-C) levels during sauna bathing

(B1: $4.38 \pm 0.62 \mathrm{mmol} / \mathrm{l}, \mathrm{p}=0.007$ ), and then before (B3: $4.25 \pm 0.47 \mathrm{mmol} / \mathrm{l}, \mathrm{p}=0.044$ ) and after the last ses$\operatorname{sion}(\mathrm{B} 4: 4.16 \pm 0.54 \mathrm{mmol} / \mathrm{l}, \mathrm{p}=0.015)$ as well as $24 \mathrm{~h}$ after the last sauna session (B5: $4.18 \pm 0.41 \mathrm{mmol} / \mathrm{l}, \mathrm{p}=0.02$ ). TC concentrations in the 1st and the 2nd week after completion of the sessions were at a lower level

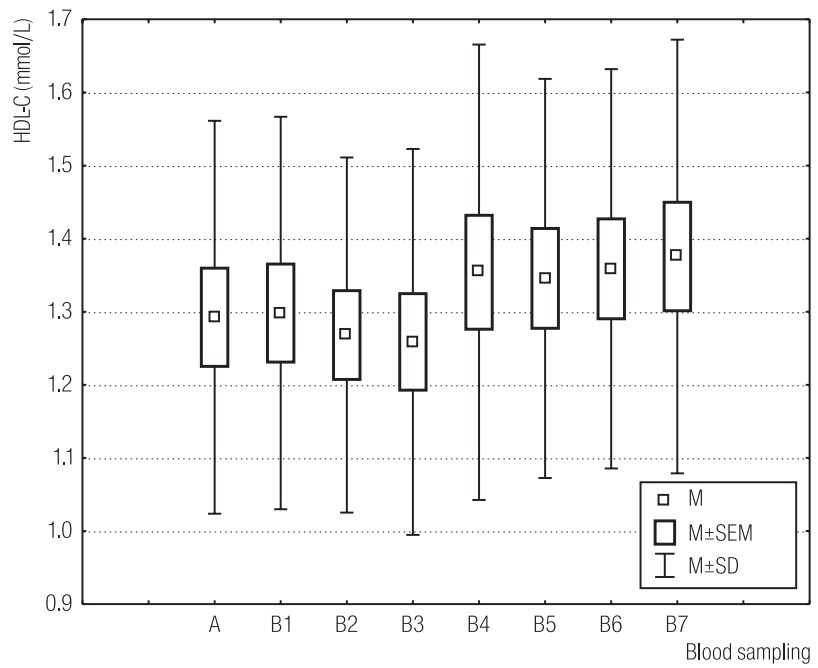

Abbreviations as in Tables 1 and 2.

Fig. 4. High-density lipoprotein cholesterol (HDL-C) levels during sauna bathing 
(B6: $4.26 \pm 0.45 \mathrm{mmol} / \mathrm{l}$ and $\mathrm{B} 7: 4.37 \pm 0.56 \mathrm{mmol} / \mathrm{l}$ ) compared to the initial level. However, these results were not statistically significant (Figure 2).

Changes in LDL cholesterol fraction occurred in a similar pattern to the changes in the total cholesterol. The initial value (A) LDL-C was $2.71 \pm 0.47 \mathrm{mmol} / \mathrm{l}$. Changes observed after $10 \mathrm{~min}$ and $24 \mathrm{~h}$ after the 1st sauna session were not statistically significant (B1: $2.67 \pm 0.45 \mathrm{mmol} / \mathrm{l}$ and B2: $2.57 \pm 0.52 \mathrm{mmol} / \mathrm{l})$. Statistically significant decreases in LDL-C level were observed in blood samples taken before (B3: $2.52 \pm 0.43 \mathrm{mmol} / \mathrm{l}, \mathrm{p}=0.013$ ) and after the 10th sauna session (B4: $2.44 \pm 0.42 \mathrm{mmol} / \mathrm{l}$, $\mathrm{p}=0.007), 24 \mathrm{~h}(\mathrm{~B} 5: 2.43 \pm 0.35 \mathrm{mmol} / \mathrm{l}, \mathrm{p}=0.01)$ and a week after completion of the series of sauna sessions (B6: $2.47 \pm 0.40 \mathrm{mmol} / \mathrm{l}, \mathrm{p}=0.03$ ). In the 2 nd week after completion of the sauna sessions, LDL-C level remained lower than the initial value (B7: $2.57 \pm 0.43 \mathrm{mmol} / \mathrm{l})$. However, this change was not statistically significant compared to the initial level (Figure 3).

No statistically significant changes were found in HDL-C levels. However, an upward tendency could be observed in the level of this cholesterol fraction, with its level insignificantly higher both after the last sauna session and on consecutive days after completion of the series of sessions compared to the initial level A: $1.29 \pm 0.27 \mathrm{mmol} / \mathrm{l}$ (Figure 4).
A statistically significant increase in the rectal temperature and the heart rate was also recorded during the sauna sessions (Table 4). The subjects had normal rectal temperature before being subjected to the 1st and 10th sauna sessions. In response to the sauna baths, after each exposure, rectal temperature increased significantly $(\mathrm{p}<0.01)$. The increase in the core body temperature after the 10th sauna session was smaller than after the 1st session, although this difference failed to reach statistical significance. Moreover, the resting rectal temperature of the subjects before the last sauna session was significantly lower $(\mathrm{p}<0.05)$ than before the 1st bath indicating an adaptive decreasing of the core body temperature due to the high temperature in the sauna.

Changes in blood plasma volume as a result of dehydration are presented in Table 5. A decline in blood plasma volume was found in the subjects examined after the 1st and the last sauna bathing sessions as a result of dehydration caused by intensive perspiration. The change in the blood plasma volume during the last session was slightly higher $(\% \Delta \mathrm{PV}=-9.67 \pm 2.93)$ than during the 1st one $(\% \Delta \mathrm{PV}=-8.13 \pm 3.52)$. The difference, however, was not statistically significant. An adaptive increase in blood plasma volume was also found after the series of sauna sessions $-\% \Delta \mathrm{PV}=6.8 \pm 4.07$.

Table 4. Changes in rectal temperature (Tre) and the heart rate (HR) during the 1st and 10th (last) sauna bathing sessions

\begin{tabular}{lcccc}
\hline \multicolumn{1}{c}{ Variable } & $\begin{array}{c}\text { Before entering } \\
\text { the sauna chamber } \\
(\mathrm{M} \pm \mathrm{SD})\end{array}$ & $\begin{array}{c}\text { In the last minute } \\
\text { of heat treatment } \\
(\mathrm{M} \pm \mathrm{SD})\end{array}$ & $\Delta$ & $\mathrm{p}$ \\
\hline Tre $\left({ }^{\circ} \mathrm{C}\right)$ during the 1st sauna session & $37.02 \pm 0.2$ & $38.56 \pm 0.30^{*}$ & $1.54 \pm 0.20$ & 0.0004 \\
Tre $\left({ }^{\circ} \mathrm{C}\right)$ during the last sauna session & $36.65 \pm 0.3^{* * *}$ & $38.13 \pm 0.23^{* *}$ & $1.48 \pm 0.34$ & 0.0004 \\
HR (beats/min) during the 1st sauna session & $69.00 \pm 5.37$ & $132.00 \pm 6.53^{*}$ & $63.00 \pm 7.51$ & 0.0004 \\
HR (beats/min) during the last sauna session & $68.25 \pm 5.16$ & $126.50 \pm 4.82^{* *}$ & $58.25 \pm 6.53$ & 0.0004 \\
\hline
\end{tabular}

$\Delta$ - calculation of the difference between the last and the first measurment of the variables.

* Statistical significance of differences at $p<0.001$ compared with the level before the 1st sauna sessions.

** statistical significance of differences at $\mathrm{p}<0.001$ compared with the level before the last sauna sessions.

*** Statistical significance of differences at $\mathrm{p}<0.05$ compared with the level before the 1 st sauna sessions.

Other abbreviations as in Table 1. 
Table 5. Changes in the blood plasma volume after sauna bathing sessions

\begin{tabular}{lccc}
\hline \multicolumn{1}{c}{ Plasma volume changes } & $\begin{array}{c}\text { After the 1st sauna session } \\
(\mathrm{M} \pm \mathrm{SD})\end{array}$ & $\begin{array}{c}\text { After the last sauna session } \\
(\mathrm{M} \pm \mathrm{SD})\end{array}$ & $\mathrm{p}$ \\
\hline$\% \Delta \mathrm{PV}$ & $-8.13 \pm 3.52$ & $-9.67 \pm 2.93$ & 0.063 \\
\hline
\end{tabular}

Abbreviations as in Table 1.

\section{DISCUSSION}

Improper blood lipid profile, which is conducive to development of arteriosclerosis and other cardiovascular conditions, is characterized by the elevated levels of LDL cholesterol fraction, total cholesterol and triacylglycerols [19]. A reduced level of HDL-C fraction represents an independent risk factor, which is negatively correlated with cardiovascular diseases [20]. An essential problem to be solved is finding a method for reduction of LDL fraction and increasing HDL-C fraction which is responsible for the reverse cholesterol transport - a process of transport of free cholesterol from peripheral and adipose tissues mainly to the liver [21]. An important role of HDL-C as an anti-atherosclerotic agent is to prevent oxidative modification of LDL-C fraction, which is an initial element of formation of the atherosclerotic plaque as well as its effect on the endothelial tissue, which improves its function through stimulation of production of nitric oxide and inhibiting apoptosis of the endothelial cells [22,23].

The results obtained by numerous researchers have demonstrated that improper levels of blood lipids and lipoproteins are present especially in people with excessively high content of the adipose tissue, which is also attributed to unhealthy diet [24]. Age represents another risk factor [25]. Other reports have found no differences in the levels of lipids/lipoproteins between young athletes and young sedentary male subjects if their body fat and BMI were similar [26,27]. In the group studied, the mean levels of total cholesterol, triacylglycerols, cholesterol of LDL and HDL fractions did not differ from the referential values.
The available scientific literature fails to report the effect of single and repeated sauna sessions on lipid profile in young men. The present study aimed to investigate the effect of the regular use of sauna on body mass and lipid profile in healthy, young, male subjects. No changes in the mean body mass were found in the subjects after 10 sauna bathing sessions that were taking place for 4 weeks. Mean BMI index also remained at the same level. This suggests that using sauna sessions did not contribute to changes in the content of adipose tissue in the men studied. In a study by Biro et al. [28], who used far infrared-ray dry sauna with the temperature of $60^{\circ} \mathrm{C}$, the researchers have demonstrated that 15 -min sauna sessions (after which the patients remained covered with blankets for $30 \mathrm{~min}$ in order to maintain the core temperature elevated by $1^{\circ} \mathrm{C}$ ) repeated for 2 weeks contribute to body mass reduction, decrease in blood pressure and glucose levels in the people with diagnosed diseases of affluence. However, postsession changes in lipid profile in the above study failed to be statistically significant [28].

The present study found a statistically significant decline in total cholesterol levels compared to the initial values measured directly after the 1st sauna session and then after the last sauna session and $24 \mathrm{~h}$ after completion of the sessions. After the 1st and the 2nd week from completion of the experiments, the total cholesterol levels remained at a lower level compared to the initial value. However, a tendency for returning of this value to the initial level was found. Changes in LDL cholesterol fractions were similar, but the statistically significant reduction in LDL-C concentration continued until the end of the 1st week after completion of the series of sessions. The study carried 
out by Pilch et al. [29] on a group of young and healthy female subjects subjected to sauna bathing sessions repeated for 7 times have demonstrated an increase in blood free fatty acids levels in the subjects who remained in a sauna chamber for 30 min continuously after the 1st session in the sauna. After 2 weeks of the experiment, the authors have found a reduction in total cholesterol and LDL cholesterol fraction levels, whereas HDL cholesterol fraction level was slightly elevated. This study did not measure these indices in the weeks following the experiment.

Although the above results point unequivocally to the advantageous effect of hyperthermia caused by sauna on the total cholesterol level and LDL fraction, contributing to reduction in their levels, there are reports that hyperthermia caused by other factors does not exhibit this effect. A study by Vangelova et al. [30], carried out among industrial workers subjected to a prolonged exposure to hot ambient temperatures of production halls, have demonstrated a significantly higher level of total cholesterol and LDL cholesterol fraction compared to the controls, who were not exposed to higher temperatures. Furthermore, a study that evaluated a group of 16 middle-aged people subjected to a series of 20-min bathing in thermal springs with temperature of $42^{\circ} \mathrm{C}$ twice a week for 3 months has found a statistically significant increase in blood total cholesterol with small and statistically insignificant changes in LDL and HDL fractions [31].

The authors of the present study observed a statistically significant decline in triacylglycerols (TAG) levels in blood samples taken both after the 1st and the 10th sauna sessions. TAG levels returned to the initial values after $24 \mathrm{~h}$ and remained unchanged after 2 weeks after completion of the sauna sessions. The results obtained for evaluation of the effect of body overheating on TAG levels are inconsistent. Both, lack of the effect of sauna on TAG levels [32], and elevated TAG levels after a single sauna session in the male subjects [33] have been reported.

The present study found a small and statistically insignificant increase in HDL cholesterol fraction level. Similar experiments, with a group of women, have revealed a statistically significant increase in HDL cholesterol fraction after 2 weeks of sauna sessions [29], which might represent a promising prognosis for prevention of cardiovascular diseases through antiatherosclerotic effect of this cholesterol fraction.

It is well established that plasma volume is increased after heat acclimation and after endurance training in humans [34]. Saat at al. [35] have suggested that expansion of the plasma volume is a crucial hemodynamic change associated with cardiovascular adjustment to the heat. In the present study we found an increase of plasma volume after series of 10 sauna sessions by $6.8 \%$. Our results support the previous findings, in which the plasma volume showed an increase by $7.1 \%$ after 12 sauna bathing sessions conducted over 3 weeks on the group of 6 male athletes [36]. These findings confirm that adaptive changes to heat stress include plasma volume expansion, which Patterson et al. [34] have attributed to the expansion of the extracellular compartment.

Also the elevated heart rate observed during sauna bathing and consequently an increase in oxygen demand in cardiac muscle, as well as rising in the core body temperature are similar to the changes in these indices observed during a moderate to intensive walking [37]. A positive effect of sauna on lipid profile demonstrated in this study is similar to the effect that can be obtained through a moderate-intensity physical exercise [38,39]. Therefore, sauna bathing seems to represent an alternative method in prevention of atherosclerosis for people with dysfunctional motor organs.

Limitation of the study - in the present study we did not measure skin temperature of the subjects. The hot phase of the sauna session induces an increase in cutaneous circulation and evaporation of the sweat from the skin is the only effective way to prevent the core body temperature from rising. The skin temperature in the sauna rises rapidly and it is reasonable to measure it. 


\section{CONCLUSIONS}

The study found that 10 complete sauna bathing sessions in a Finnish sauna cause reduction in total cholesterol (TC) and LDL cholesterol fraction levels during the sessions and a gradual return of these levels to the initial level during the 1st and the 2nd week after the experiment. A small and statistically insignificant increase in HDL-C level and the transient decline in triacylglycerols (TAG) were observed after the sauna sessions. It was found that a positive effect of sauna on lipid profile is similar to the effect that can be obtained through a moderate-intensity physical exercise. Therefore, sauna bathing might be an alternative method in prevention of atherosclerosis in the case of people with dysfunctional motor organs.

\section{REFERENCES}

1. Boraita A. Plasma lipid profile is improved by participation in sports, but at what intensivity? Rev Esp Cardiol. 2004;57(6): 495-8, http://dx.doi.org/10.1016/S1885-5857(06)60624-5.

2. Kipreos G, Tripolitsioti A, Stergioulas A. The effects of anaerobic training in serum lipids and arachidonic acid metabolites. Biol Exerc. 2010;6(2):5-12, http://dx.doi.org/10.4127/ jbe.2010.0036.

3. Lira FS, Yamashita AS, Uchida MC, Zanchi NE, Gualano B, Martins E, et al. Low and moderate, rather than high intensity strength exercise induces benefit regarding plasma lipid profile. Diabetol Metab Syndr. 2010;2:31, http://dx.doi. org/10.1186/1758-5996-2-31.

4. Ruiz JR, Mesa JLM, Mingorance I, Rodríguez-Cuartero A, Castillo MJ. Sports requiring stressful physical exertion cause abnormalities in plasma lipid profile. Rev Esp Cardiol (English Edition). 2004;57(6):499-506, http://dx.doi.org/10.1016/ S1885-5857(06)60625-7.

5. Booth FW, Chakravarthy MV, Gordon SE, Spangenburg EE. Waging war on physical inactivity: Using modern molecular ammunition against an ancient enemy. J Appl Physiol. 2002; 93(1):3-30, http://dx.doi.org/10.1152/japplphysiol.00073.2002.
6. O'Donnell MJ, Xavier D, Liu L, Zhang H, Chin SL, RaoMelacini P, et al. Risk factors for ischaemic and intracerebral haemorrhagic stroke in 22 countries (The INTERSTROKE study): A case-control study. Lancet. 2010;376(9735): 112-23, http://dx.doi.org/10.1016/S0140-6736(10)60834-3.

7. Iguchi M, Littmann AE, Chang SH, Wester LA, Knipper JS, Shields RK. Heat stress and cardiovascular, hormonal, and heat shock proteins in humans. J Athl Train. 2012;47(2): 184-90.

8. Crinnion WJ. Sauna as a valuable clinical tool for cardiovascular, autoimmune, toxicant-induced and other chronic health problems. Altern Med Rev. 2011;16(3):215-25.

9. Blum N, Blum A. Beneficial effects of sauna bathing for heart failure patients. Exp Clin Cardiol. 2007;12(1):29-32.

10. Hannuksela ML, Ellahham S. Benefits and risks of sauna bathing. Am J Med. 2001;110(2):118-26, http://dx.doi. org/10.1016/S0002-9343(00)00671-9.

11. Kukkonen-Harjula K, Kauppinen K. Health effects and risks of sauna bathing. Int J Circumpolar Health. 2006;65(3): 195-205, http://dx.doi.org/10.3402/ijch.v65i3.18102.

12. Sawicka A, Brzostek T, Kowalski R. Effects of sauna bath on the cardiovascular system. Med Rehabil. 2007;11(1):15-22.

13. Craig CL, Marshall AL, Sjorstrom M, Bauman AE, Booth ML, Ainsworth BE, et al. International physical activity questionnaire: 12-country reliability and validity. Med Sci Sports Exerc. 2003;35(8):1381-95, http://dx.doi. org/10.1249/01.MSS.0000078924.61453.FB.

14. Jarosz M, Bułhak-Jachymczyk B. [Standards of human nutrition. Basic prevention of obesity and non-communicable diseases]. Warszawa: Wydawnictwo Lekarskie PZWL; 2008. Polish.

15. Kunachowicz H, Nadolna I, Przygoda B, Iwanow K. [Tables of nutritive value of food products]. Warszawa: Instytut Żywności i Żywienia; 1998. Polish.

16. Slaughter MH, Lohman TG, Boileau R, Horswill CA, Stillman RJ, van Loan MD, et al. Skinfold equations for estimation of body fatness in children and youth. Hum Biol. 1988;60(5):709-23. 
17. Johansen LB, Videbaek R, Hammerum M, Norsk P. Underestimation of plasma volume changes in humans by hematocrit/hemoglobin method. Am J Physiol. 1998;274 (1 Pt 2):R126-30.

18. Kraemer RR, Brown BS. Alterations in plasma-volume-corrected blood components of marathon runners and concomitant relationship to performance. Eur J Appl Physiol. 1986;55(6):579-84, http://dx.doi.org/10.1007/BF 00423200 .

19. Santos-Gallego CG, Badimon JJ. High-density lipoprotein and cardiovascular risk reduction: Promises and realities. Rev Esp Cardiol. 2012;65(4):305-8, http://dx.doi. org/10.1016/j.rec.2011.10.023.

20. Chapman MJ. Therapeutic elevation of HDL-cholesterol to prevent atherosclerosis and coronary heart disease. Pharmacol Ther. 2006;111(3):893-908, http://dx.doi. org/10.1016/j.pharmthera.2006.02.003.

21. Biggerstaff KD, Wooten JS. Understanding lipoproteins as transporters of cholesterol and other lipids. Adv Physiol Educ. 2004;28:105-6, http://dx.doi.org/10.1152/advan.00048.2003.

22. Cromwell WC. High-density lipoprotein associations with coronary heart disease: Does measurement of cholesterol content give the best result? J Clinic Lipidol. 2007;1(1): 57-64, http://dx.doi.org/10.1016/j.jacl.2007.01.002.

23. Mineo C, Yuhanna IS, Quon MJ, Shaul PW. High density lipoprotein-induced endothelial nitric-oxide synthase activation is mediated by Akt and MAP kinases. J Biol Chem. 2003;278(11):9142-9, http://dx.doi.org/10.1074/jbc. M211394200.

24. Després JP. 7 Dyslipidaemia and obesity. Baillière's Clin Endocrinol Metab. 1994;8(3):629-60, http://dx.doi.org/10.1016/ S0950-351X(05)80289-7.

25. Martins RA, Veríssimo MT, Coelho de Silva MJ, Cumming SP, Teixeira AM. Effects of aerobic and strength-based training on metabolic health indicators in older adults. Lipids Health Dis. 2010;9:76, http://dx.doi.org/10.1186/1476511X-9-76.
26. Petridou A, Lazaridou D, Mougios V. Lipidemic profile of athletes and non-athletes with similar body fat. Int J Sport Nutr Exerc Metab. 2005;15(4):425-32.

27. Imamoglu O, Atan T, Kishali NF, Burmaoglu G, Akyol P, Yildirim K. Comparison of lipid and lipoprotein values in men and women differing in training status. Biol Sport. 2005;22(3):261-70.

28. Biro S, Masuda A, Kihara T, Tei C. Clinical implications of thermal therapy in lifestyle-related diseases. Exp Biol Med. 2003;228(10):1245-9.

29. Pilch W, Szyguła Z, Klimek A, Pałka T, Cisoń T, Pilch P, et al. Changes in the lipid profile of blood serum in women taking sauna baths of various duration. Int J Occup Med Environ Health. 2010;23(2):167-74, http://dx.doi.org/10. 2478/v10001-010-0020-9.

30. Vangelova K, Deyanov C, Ivanova M. Dyslipidemia in industrial workers in hot environments. Cent Eur J Public Health. 2006;14(1):15-7.

31. Sakurai R, Fujiwara Y, Saito K, Fukaya T, Kim MJ, Yasunaga $\mathrm{M}$, et al. Effects of a comprehensive intervention program, including hot bathing, on overweight adults: A randomized controlled trial. Geriatr Gerontol Int. 2013;13(3):638-45, http://dx.doi.org/10.1111/j.1447-0594.2012.00955.x.

32. Leppäluoto J, Tuominen M, Väänänen A, Karpakka J, Vouri J. Some cardiovascular and metabolic effects of repeated sauna bathing. Act Phys Scand. 1986;128(1):77-81, http://dx.doi.org/10.1111/j.1748-1716.1986.tb07952.x.

33. Szyguła Z, Podolec Z, Moskala J, Zuchowicz A. Some metabolic and hormonal changes as an effect of repeated sauna bathing. Act Physiol Pol. 1990;41:233-4.

34. Patterson MJ, Stocks JM, Taylor NA. Sustained and generalized extracellular fluid expansion following heat acclimation. J Physiol. 2004;559(pt 1):327-34, http://dx.doi. org/10.1113/jphysiol.2004.063289.

35. Saat M, Sirisinghe RG, Singh R, Tochihara Y. Effects of short-term exercise in the heat on thermoregulation, blood parameters, sweat secretion and sweat composition of tropic-dwelling subjects. J Physiol Anthropol Appl Human Sci. 2005;24(5):541-9, http://dx.doi.org/10.2114/jpa.24.541. 
36. Scoon GS, Hopkins WG, Mayhew S, Cotter JD. Effect of post-exercise sauna bathing on the endurance performance of competitive male runners. J Sci Med Sport. 2007;10(4): 259-62, http://dx.doi.org/10.1016/j.jsams.2006.06.009.

37. Saadat H, Sadeghi R, Motamedi MR, Namazi MH, Safi M, Vakili H, et al. Potential role of thermal therapy as an adjunct treatment in congestive heart failure. J Tehran Univ Heart Cent. 2009;4(3):149-58.
38. Durstine JL, Grandjean PW, Davis PG, Ferguson MA, Alderson NL, DuBose KD. Blood lipid and lipoprotein adaptations to exercise. Sports Med. 2001;31(15):1033-62, http:// dx.doi.org/10.2165/00007256-200131150-00002.

39. Leon AS, Sanchez OA. Response of blood lipids to exercise training alone or combined with dietary intervention. Med Sci Sports Exerc. 2001;33(6 Suppl):502-15, http://dx.doi. org/10.1097/00005768-200106001-00021.

This work is available in Open Access model and licensed under a Creative Commons Attribution-NonCommercial 3.0 Poland License - http://creativecommons.org/ licenses/by-nc/3.0/pl/deed.en. 